\title{
DETECTION OF POLYCYCLIC AROMATIC HYDROCARBON IN CHARCOAL - GRILLED MEAT WITH AND WITHOUT NATURAL ADDITIVES
}

\author{
ARWA NASSAR ${ }^{1}$; SHAFIK, S. ${ }^{2}$ and ABDELAZIEM, O. \\ ${ }^{1}$ Food Hygiene Unit Animal Health Research Institute -Mansoura \\ 2 Biochemical Unit. Animal Health Research Institute -Mansoura
}

Received: 31 March 2018; Accepted: 30 April 2018

\begin{abstract}
This study was conducted for detection of PAHs in both non marinated charcoal grilled kebab and kofta (5 of each) as a control samples and marinated charcoal grilled kebab and kofta (15 of each) using Gas liquid chromatography equipped with flam ionization detector GC/FID. Our results indicate the presence of Acenaphtene, Benzo (a) pyrene, Fluroanthene, Fluorene and Penanthrene (ppm) with a mean value of $0.027,0.0059,0.72,0.008$ and 0.032 for kebab and $0.055,0.023, \mathrm{ND}, 0.04$ and $0.023 \mathrm{ppm}$ for kofta respectively while Acenaphthylene was not detected in charcoal grilled kebab and kofta in non-marinated control samples. Moreover, after marination the mean values were $0.0041, \mathrm{ND}, 0.068$, ND and 0.0134 while in kofta they were $\mathrm{ND}, \mathrm{ND}, 0.093,0.0062$ and ND respectively but Acenaphthylene in kofta was $0.010 \mathrm{ppm}$. However consumer not believed to be exposed to these levels so the application of this simple method by addition of natural preservatives (marination) at home and restaurants is important to reduce exposure of consumer to this group of carcinogenic agents produced during meat processing. The public health significance and economic importance of PAHs as well as recommendations for eating low PAHs meat were also discussed.
\end{abstract}

Key words: Polycyclic Aromatic Hydrocarbon - gas chromatography kebab - kofta - Benzo (a) pyrene

\section{INTRODUCTION}

Polycyclic aromatic hydrocarbons (PAHs) are hydrocarbons - organic compounds containing only carbon and hydrogen - that are composed of multiple aromatic rings $\mathrm{PAHs}$, are neutral non-polar and lipophilic molecules found in coal and in tar deposits. They are also produced by the incomplete combustion of organic matter (Nisbet and Lagoy, 1992).

Grilled foods are increasingly popular both at home and in restaurants; however, based on many studies, these foods present an elevated health risk to the population due to the higher levels of carcinogens found in such products compared to foods prepared by alternative cooking methods (Sundararajan et al., 1999).

The US Environmental Protection Agency (US-EPA) (2002) proposed to use a selection of 16 PAHs which are frequenly found in environmental monitoring samples, namely, naphthalene (Na) acenaphthene (Ac), acenaphthylene (Ace), fluorene (F), anthracene $(\mathrm{A})$, phenanthrene $(\mathrm{Pa})$, fluoranthene $(\mathrm{Fl})$, pyrene $(\mathrm{P})$,

Corresponding author: Dr. ARWA NASSAR

E-mail address: basma22toto@gmail.com

Present address: Food Hygiene Unit Animal Health Research Institute-Mansoura
Benzo (a) anthracene (BaA), chrysene (Ch), benzo (b) fluoranthene $(\mathrm{Bbf})$ benzo $(\mathrm{k})$ fluoranthene $(\mathrm{BKF})$, benzo (a) pyrene $(\mathrm{BaP})$, dibenzo $(\mathrm{a}, \mathrm{h})$ anthracene $(\mathrm{DhA})$, benzo $(\mathrm{g}, \mathrm{h}, \mathrm{i})$ perylene $(\mathrm{BgP})$, indeno $(1,2,3$ cd) pyrene (IP).

European commission scientific committee on food selected four PAHs in the 15 priority PAHs as the most sutible indicators of carcinogenic PAHs in foods these four PAHs are benzo (a) pyrene, benzo (a) anthracene, chrysene and benzo (b) flouranththene.

The highest benzo (a) pyrene concentrations observed in barbecued meat products have been reported to be $1.5 \mu \mathrm{g} / \mathrm{kg}$ for beef patties (Kazerouni et al., 2001 and FSTA, 2007) and $0.313 \mu \mathrm{g} \backslash \mathrm{kg}$ for beef steaks (Aygun and Kabadayi, 2005).

It has also reported that the concentration of PAHs in barbecued food varies due to parameters such as fat content of food beside dripping of fat over the flame (Chen and Chen, 2001; FSTA, 2007), food type (Kazerouni et al., 2001 and Aaslyng et al., 2013), heat temperature and direct contact with heat source (Garcia-Falcon and Simal-Gandara, 2005; Reinik et al., 2007; Chung et al., 2011).

It is important to note that PAHs could be generated during cooking processes such as grilling, roasting, smoke curing and drying and this is the main reason 
for PAHs occurrence in food (Šimko, 2002; Chung et al., 2011). According to The Scientific Committee on Food (SCF), Benzo [a] pyrene can be used as indicator for the presence of PAHs in food and their potential toxicity (European Commission, 2002) but the European food safety authority. (EFSA) stated that benzo [a] pyrene alone is not a sutible indicator for this purpose instead of other eight PAHs with potential carcinogenicity (EFSA, 2008) these eghit specifie PAHs are $\mathrm{BaA}, \mathrm{Ch}, \mathrm{BbF}, \mathrm{BkF}, \mathrm{BjF}, \mathrm{BaP}, \mathrm{IP}$ and DhA which are classified as group $2 \mathrm{~B}$, probable human carcinogenics (European Commission, 2002).

Some studies try to reduce PAHs levels in charcoal grilled meat, three treatments wrapping with aluminum foil, preheating (steam and microwave) and use of marinating sauces (such as turmeric, salt, lemon,...) have been investigated. Using these pretreatments before charcoal grilling resulted in reduced levels of carcinogenic PAHs in grilled meat samples (Farhadian et al., 2011\&2012). However, grilling samples of meat marinated for four hours had the powerful effect in minimizing PAHs concentration in meat dishes (Farhadian et al., 2012).

PAHs are widely distributed in the environment a number of them, such as benzo $[a]$ pyrene, are carcinogenic and mutagenic, and they are widely believed to make a substantial contribution to the overall burden of cancer in humans. Their presence in the environment is reflected in their presence at detectable levels in many types of uncooked food. In addition, cooking processes can generate PAHs in food, (Phillips, 1999).

Meat dishes prepared by charcoal grilling are popular and favorite food in Egypt as well as in other Arabian countries. Therefore the aim of this study was to throw the light on PAHs concentration in kebab and kofta as well as to determin the effect of addition of natural additives to meat (marination) prior to charcoal grilling as a trial to reach a most sutible methods which prevent or reduce the PAHs formation during meat processing. The present study consider a first trial to detect concentrations of PAHs in grilled kabab and kofta and effect of marinating on their concentrations.

\section{MATERIALS AND METHODS}

Forty samples of charcoal grilled meat (Kebab) and charcoal grilled kofta (20 of each) Samples were collected for detection and determination of polycyclic aromatic hydrocarbons (PAHs) compound residues, as follows:

(A) Ten samples of charcoal grilled meat (kebab) and kofta (5 of each) were collected from Mansoura city,
El Dakhlia Governorate, Egypt and examined directly (non- marinated control).

(B) Thirty samples of fresh beef meat (divided into two parts one for kebab and the other used for kofta, 15 of each) were marinated and charcoal grilled then examined after marinating according to (Badry, 2010) and (Farhadin et al., 2012).

Beef meat used for kebab and kofta were marinated by yoghurt, salt, turmeric, mustard, curry powder, lemon juice Cardamom, vinegar and onion, all these ingredients were mixed in a blender and added to the beef meat for 4 hours at refrigerator $\left(4^{\circ} \mathrm{C}\right)$ until used for charcoal grilling. The samples were identified and kept frozen till the analysis was carried out

\section{Analysis of the polycyclic aromatic hydrocarbos (PAHs) residues:}

The analysis of PAHs residues was carried out extraction procedures, clean up and estimation of PAHs levels by gas chromatography were conducted in Pesticide Residue Department Central Pesticide Lab., Agriculture Research Center, Giza.

\section{Extraction}

Exactly $20 \mathrm{gm}$ each of the examined samples were grinded in a mortar with anhydrous sodium sulphate (2gm). The mixture was then extracted with $60 \mathrm{ml}$ of hexane-acetone (1-1) (v/v) mixture. The mixture was filtered and the tissue was extracted twice more. Organic solvent fractions were combined and filtered through filter paper with $1 \mathrm{gm}$ anhydrous sodium sulphate. The extraction was evaporated to about 2 $\mathrm{ml}$, then the extract was transferred to a round bottom flask and $100 \mathrm{ml}$ of $10 \%$ aqueous methanolic potassium hydroxide were added, and the mixture was refluxed for 3 hours in order to saponify the lipids. At the end, the content of the round bottom flask was transferred to a separator funnel and rinsed with $150 \mathrm{ml}$ of methanol-water $(4: 1)$, (v/v) mixture then extracted with hexane $(80 \mathrm{ml})$ to recover the non soponified lipids. The hexane phase was concentrated down to $1.5 \mathrm{ml}$ with an evaporator.

\section{Clean up (Villeneuve et al., 1999)}

Clean up was achieved with a silica/alumina column. Aromatic hydrocarbons were eluted with $30 \mathrm{ml}$ of a mixture of hexane and dichloromethane (90:10), $(\mathrm{v} / \mathrm{v})$. The volume of the eluted fraction was reduced to $1 \mathrm{ml}$ and analyzed by a gas liquid chromatography equipped with a flame ionization detector GC/FID.

\section{Preparation of blank solution}

The same volume of solvents and anhydrous sodium sulphate, used in extraction of polycyclic aromatic hydrocarbon from the examined samples were subjected to the same procedures as for the examined 
samples to detect any possible traces of the studied PAHs in the solvents or distilled water.

Gas Chromatography Analysis (Moret and conter 2000)

The polycyclic aromatic hydrocarbon fraction was injected into a gas liquid chromatography equipped with flam ionization detector GC/FID. Analysis was conducted on a HP-608 (Agilent, Folsom, CA) fused silica capillary column of 30 length, $0.53 \mathrm{~mm}$ id., and $0.5 \mu \mathrm{m}$ film thickness. The oven temperature was programmed from an initial temperature $100 \mathrm{C}^{\circ}(2$ min hold) to $260 \mathrm{C}^{\circ}$ at rate of $6 \mathrm{C}^{\circ} / \mathrm{min}$ and was maintained at $260 \mathrm{C}^{\circ}$ for $15 \mathrm{~min}$. Injector and detector temperature was maintained at 280 and 300
$\mathrm{C}^{\circ}$ respectively. Nitrogen was used as a carrier at flow rate of $4 \mathrm{ml} / \mathrm{min}$.

Determination of percentage rate of recovery:

Recovery was carried out by the addition of PAHs standards mixture at three levels of $1,5,10 \mu \mathrm{g}$. All data were corrected according to the recovery percentage values. Compounds were identified by matching retention time against those authentic Standards.

Statistical analysis

Statistical analysis was carried out by using (SPSS 18 2010).

\section{RESULTS}

Table1: Concentration of different PAHs residues (ppm) detected in non-marinated Kebab and charcoal grilled Kofta $[\mathrm{N}=10$ (5 of each)].

\begin{tabular}{ccccccccc}
\hline Samples & \multicolumn{4}{c}{ Kebab } & \multicolumn{3}{c}{ Kofta } \\
\hline PAHs & No & $\%$ & Rang & Mean \pm SE & No & $\%$ & Rang & Mean \pm SE \\
\hline Acenaphthylene & ND & ND & ND & ND & ND & ND & ND & ND \\
\hline Acenaphtene & 2 & 40 & $\mathbf{0 - 0 . 0 4}$ & $\mathbf{0 . 0 2 7} \pm 0.013$ & 2 & 40 & $\mathbf{0 - 0 . 0 7}$ & $\mathbf{0 . 0 5 5} \pm 0.0015$ \\
\hline Benzo (a) pyrene & 2 & 40 & $\mathbf{0 - . 0 0 8 8}$ & $\mathbf{0 . 0 0 5 9} \pm 0.0029$ & 2 & 40 & $\mathbf{0 - 0 . 0 2 6}$ & $\mathbf{0 . 0 2 3} \pm \mathbf{0 . 0 0 3}$ \\
\hline Fluroanthene & 4 & $\mathbf{8 0}$ & $\mathbf{0 - 2 . 4}$ & $\mathbf{0 . 7 2} \pm 0.56$ & ND & ND & ND & ND \\
\hline Fluorene & 2 & 40 & $\mathbf{0 - 0 . 0 1}$ & $\mathbf{0 . 0 0 8} \pm 0.0015$ & 2 & 40 & $\mathbf{0 - 0 . 0 6}$ & $\mathbf{0 . 0 4} * \mathbf{0 . 0 0 2}$ \\
\hline Penanthrene & 2 & 40 & $\mathbf{0 - 0 . 0 5 5}$ & $\mathbf{0 . 0 3 2} \pm 0.023$ & 3 & $\mathbf{6 0}$ & $\mathbf{0 - 0 . 0 5 5}$ & $\mathbf{0 . 0 2 3} \pm 0.0015$ \\
\hline
\end{tabular}

ND: Non Detectable (below the detection limit) $\quad \mathrm{P}^{*}<0.05$ by using t-test.

Table 2: Concentration of different PAHs residues $(\mathrm{ppm})$ detected in marinated Kebab and charcoal grilled Kofta $[\mathrm{N}=30$ (15 of each)].

\begin{tabular}{|c|c|c|c|c|c|c|c|c|}
\hline \multirow{2}{*}{$\frac{\text { Samples }}{\text { PAHS }}$} & \multicolumn{4}{|c|}{ Kebab } & \multicolumn{4}{|c|}{ Kofta } \\
\hline & No & $\%$ & Range & Mean \pm SE & No & $\%$ & Range & Mean \pm SE \\
\hline Acenaphthylene & ND & ND & ND & ND & 3 & 20 & 0- 0.018 & $0.010 \pm 0.0040$ \\
\hline Acenaphtene & 3 & 20 & $0-0.008$ & $0.0041 \pm .0019$ & ND & ND & ND & ND \\
\hline Benzo (a) pyrene & ND & ND & ND & ND & ND & ND & ND & ND \\
\hline Fluroanthene & 5 & 33.3 & 0- 0.099 & $0.068 \pm 0.0030$ & 2 & 13.3 & 0-0.099 & $0.093 * \pm 0.0055$ \\
\hline Fluorene & ND & ND & ND & ND & 4 & 26.6 & $0-0.0064$ & $0.0062 \pm 0.00008$ \\
\hline Penanthrene & 5 & 33.3 & 0-.0040 & $0.0134 \pm 0.0006$ & ND & ND & ND & ND \\
\hline
\end{tabular}

ND: Non Detectable (below the detection limit) $\quad \mathrm{P}^{*}<0.05$ by using t-test.

Table 3: Incidence and number of grilled non marinated and marinated kofta and kebab under and above permissible limits of Benzo (a) pyrene concentration.

\begin{tabular}{cccccccccc}
\hline \multirow{2}{*}{ BAP } & \multicolumn{3}{c}{ Non marinated } & \multicolumn{3}{c}{ Marinated } \\
\cline { 2 - 10 } & \multicolumn{2}{c}{ Kebab } & \multicolumn{2}{c}{ Kofta } & \multicolumn{2}{c}{ Kebab } & \multicolumn{2}{c}{ Kofta } \\
\cline { 2 - 10 } & No & $\%$ & No & $\%$ & No & $\%$ & No & $\%$ \\
\hline BAP under P.L.M & ND & ND & ND & ND & ND & ND & ND & ND \\
\hline BAP above P.L.M & 2 & 40 & 2 & 40 & ND & ND & ND & ND \\
\hline
\end{tabular}

ND: Non Detectable (below the detection limit)

Maximum Permissible limits (P.L.M.) for Benzo (a) pyrene (BAP) in smoked meat products is $0.005 \mathrm{ppm}$ (EC, 2006). 
Fig (1) Comparsion between marinated and non-marinated charcoal grilled meat (kebab) and kofta samples according to total PAHs formation with mean value.

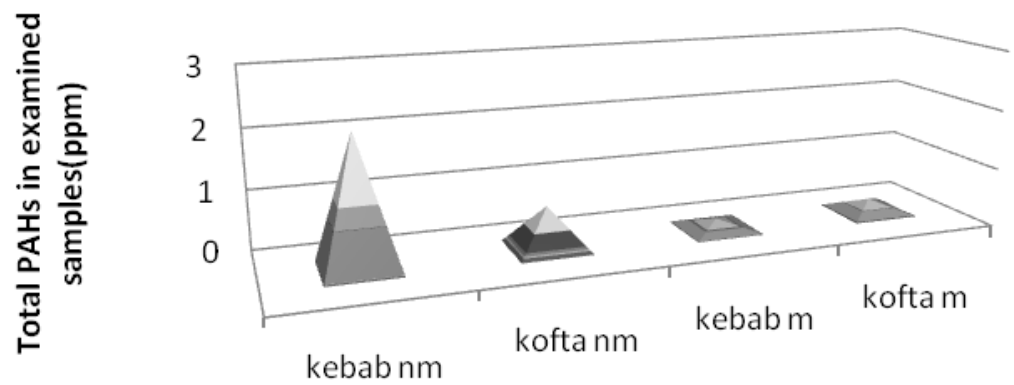

M: marinated - $\mathrm{nm}$ : non marinated .

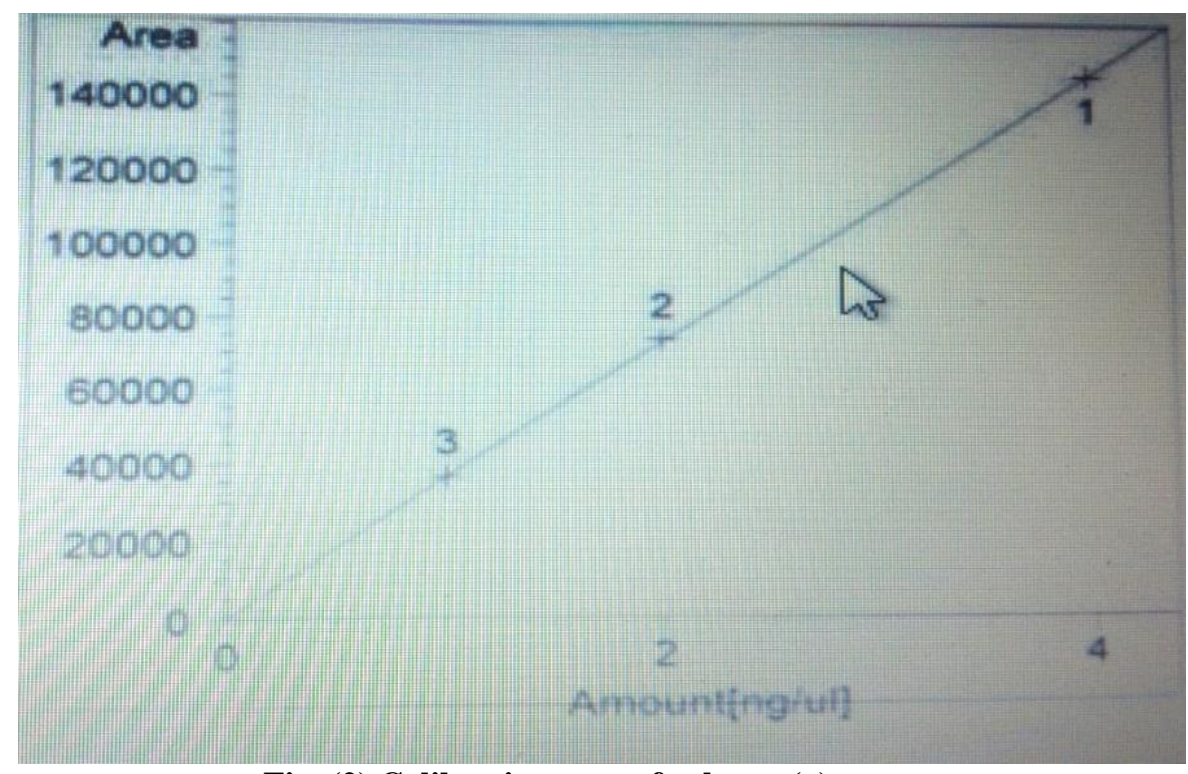

Fig. (2) Calibration curve for benzo(a) pyrene

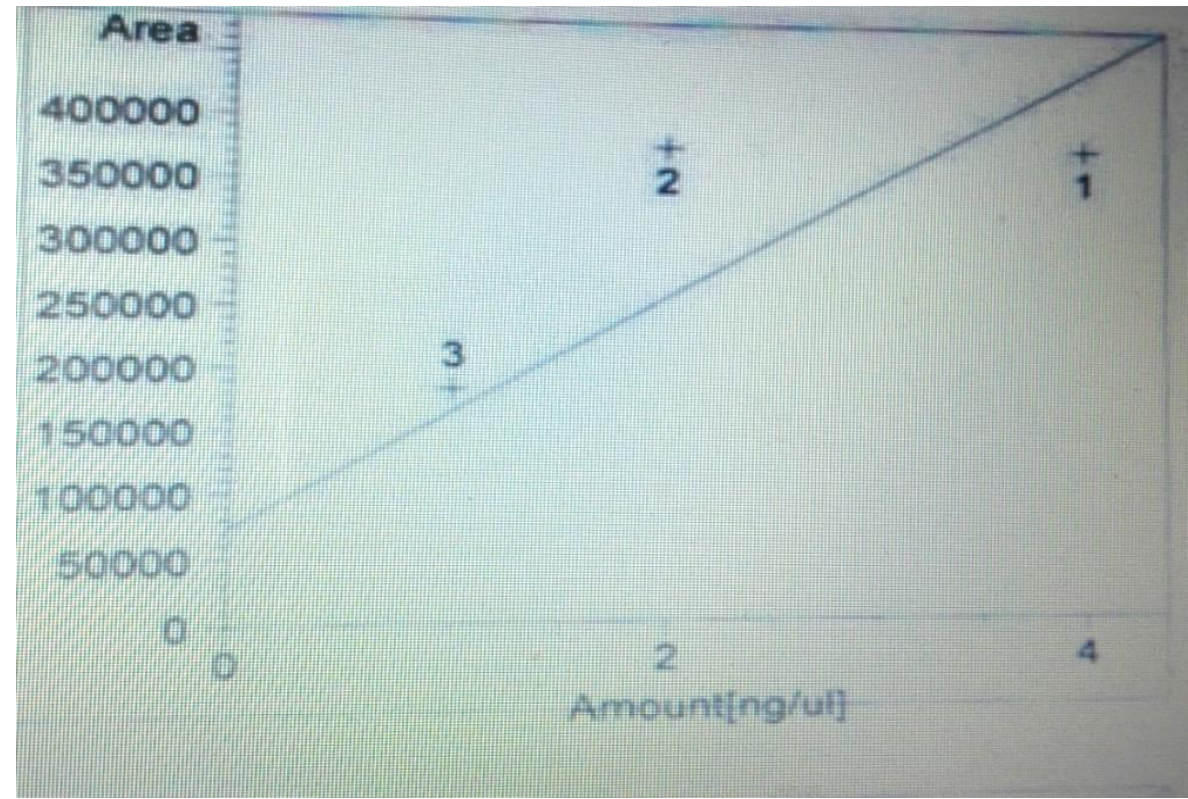

Fig. (3) Calibration curve for phenanthrene 


\section{DISCUSSION}

Consumption of meat is increasing day by day due to its nutritional value and palatable flavor. PAHs, are formed when juices from meat drip onto coals or other hot surfaces and create smoke. The smoke contains these carcinogens, which are deposited onto the surface of meat as it swirls around the food.

PAHs compounds contaminate meat by grilling as it is essential step for enhancing the aroma that distinguishes the flavor of one food from another. Aroma depends upon the vapour pressure of food constituents and on the interaction of volatile compounds with non-volatile compounds (Laing and Jink, 1996).

Marinating which is commonly used method involves injection, tumbling or immersion to disperse in the muscle tissue. The marinating ingredients are used to improve color, tenderness, increase shelf life, may affect lipid oxidation and decrease PAHs as shown in Table 1. The mean concentration of Acenaphtene, Benz(a) pyrene, Fluroanthene, Flurorene and Penanthrene (ppm) (Fig. 3) are 0.027, 0.0059, 0.72, 0.008 and 0.032 for kebab and $0.055,0.023$, ND, 0.04 and 0.023 for kofta respectively while Acenaphthylene could not be detected in charcoal grilled kebab and kofta. Similar results were obtained by Mishref (2014) while higher results were obtained by (Gorji et al., 2016).

The incidence of PAHs in the examined samples were 40, 40, 80, 40 and $40 \%$ for Acenaphtene, Benz(a) pyrene, Fluroanthene, Flurorene and Penanthrene in kebab and 40, 40, ND, 40 and $60 \%$ for kofta respectively. There were a significant increase in kofta more than kebab. The significant difference in PAHs concentration between kebab and kofta may be due to the method of grilling as kebab composed of pieces of whole meat take a long time for grilling which lead to accumulation of large amount of PAHs but kofta take low time for grilling as it composed of minced meat.

In the other hand, the addition of natural additives for kebab and kofta mainly lemon juice induces about $72 \%$ reduction of PAHs levels when applied to meat prior to charcoal grilling (Orecchioand Papuzza, 2009). On the other hands, additives have strongly antioxidant natural properites enables these foods to engulf carcinogenic compounds, these functional foods are the potent source of bioactive phenolic compounds (Hazra et al., 2010).

These bioactive compounds are acidic in nature to engulf the carcinogenic compounds or free radicals by which the concentration of PAHs to be reduced.
By observing Table 2 we found that Acenaphtene, Benz(a) pyrene, Fluroanthene, Flurorene and Penanthrene concentration in kebab after marinationare 0.0041 , ND, 0.068, ND and 0.0134 while in kofta they are ND, ND,0.093, 0.0062 and ND ppm respectively but the level of Acenaphthylene in koftais 0.010. (European COMMISSION REGULATION 2006) advise to continue to monitor the presence of PAHs in traditionally smoked meat and smoked meat products and shall establish programmes to implement good smoking practices where possible, within the limits of what is economically feasible and what is possible without losing typical organoleptic characteristics of those products.

From Table 3 it is evident that Benzo (a) pyrene exceeded the permissible limit before marination (Fig.2) and disappeared completely after marination which indicate the positive effect of marination.

Many researches illusterated the importance of cooking time as an important factor in production of PAHs in food.as PAHs formation is favored at a temperature range of 500-900 ${ }^{\circ} \mathrm{C}$ Most of these studies have concluded that the level of PAHs in food can be reduced by minimizing grilling time (Phillips, 1999; Kazerouni et al., 2001; Terzi et al., 2008). Fig (1) shows the positive effect of natural additives on reduction of PAHs formation.

In both samples kebab and kofta which agree with that reported by (Beata, 2011, Farhadian et al., 2012 and Mishref, 2014). The reduction effect of marinating on PAHs formation may be due to presenece of onion and garlic which contain a lot of organic sulfur compounds that prevent maillard reactions (Nursten, 2005; Gibis, 2007). Carcinogenic compounds such as heterocyclic aromatic amines were inhibited by onion and garlic as reported by (Shon et al., 2004).

PHAs can be reduced by following certain practices of cooking as addition of compounds with antioxidative properties.

\section{CONCLUSION AND RECOMMENDATIONS}

The obtained results of this study have shown that addition of natural additives (marination) of meat prior to charcoal grilling process have the maximum effects in reduction of PAHs. The levels of PAHs found in marinated kebab conducting more studies on the effects of different marinade ingredients is necessary in an effort to determine the best marinade treatments that are responsible for PAHs formation in grilled meat. On the other hand, safety procedures are important in preparing meat dishes which is popular worldwide. 


\section{REFERENCES}

Aaslyng, M.D.; Duedahl-Olesen, L.; Jensen, K. and Meinert, (2013): Heterocyclic amines and polyaromatic hydrocarbones in pork, beef and chicken after home-barbequing by Danish consumers. Meat Science, 93,85-91.

Aygün, S.F. and Kabadayi, F. (2005): Determination of benzo [a] pyrene in charcoal grilled meat samples by HPLC with fluorescence detection. International Journal of Food Sciences and Nutrition, 56, 581-585

Badry, N. (2010): Effect of household cooking methods and some food additives on polycyclic aromatic hydrocarbons (PAHs) formation in chicken meat. World Appl. Sci. J9, 963-974.

Beata, J. (2011): HPLC - flouresence analysis of polycyclic aromatic hydrocarbons (PAHs) in pork meat and its gravy fried without additives and inThe presence of onion and garlic. Food chemistry 126, 1344-1353.

Chen, B.H. and Chen, Y.C. (2001): Formation of polycyclic aromatic hydrocarbons in the smoke for heated model lipids and food lipids. Journal of Agricultural and Food Chemistry, 49, 5238-5243.

Chung, S.Y.; Yttella, R.R.; Kim, J.S.; Kwon, K.; Kim, M.C. and Min, D.B. (2011): Effects of grilling and roasting on the levels of polycyclic aromatic hydrocarbons in beef and pork. Food Chemistry, 129, 1420-1426.

EC (2006): Commission regulation 188/2006/ EC of 19 December 2006 setting maximum levels for certain contaminants in foodstuff. Official Journal of the European Union 1364, 5-24.

EFSA (European Food Safety Authority) (2008): Scientific opinion of the panel on contaminants in the food chain on a request form the European Commission on polycyclic aromatic hydrocarbons in food. EFSA Jounal, 724, 1-114.

European Commission Scientific Committee on Foods (2002)(SCF): Opinion of scientific committee on food on the risks to human health of polycyclic aromatic hydrocarbons in foods expressed on fourth December 2002. Brussels, European commission, health and consumer protection.

FSTA (Food Standard Agency) (2007): FD 06/13. Investigation of the formation of PAHs in foods prepared in the home and from catering outlets to determine the effects of frying, grilling, barbecuing, toasting and roasting by White, S., and Rose, M.

Farhadian, A.; Jinap, S.; Hanifah, H.N. and Zaidul, I.S. (2011): Effects of meat preheating and wrapping on the levels of polycyclic aromatic hydrocarbons in charcoal - grilled meat. Food Chemistry, 124, 141-146.
Farhadian, A.; Jinap, S.; Faridah, A. and Zaidul, I.S.M. (2012): Effects of marinating in the formation of polycyclic aromatic hydrocarbons (benzo [a] pyrene, benzo [b] fluoranthene and flouranthene) in grilled beef meat Journal of Food Control 28, 420-425.

Garcia-Falcon, M. and Simal-Gandara, J. (2005): Polycyclic aromatic hydrocarbons in smoke from different woods and their transfer during traditional smoking into chorizo sausages with collagen and tripe casings. Food Additives and Contaminants: Part A, 22,1-8.

Gibis, M. (2007): Effect of oil marinades with garlic, onion, and lemon juice on the formation of heterocyclic aromatic amines in fried beef patties. Journal of Agriculture and Food Chemistry, 55(25), 10240 -10247.

Gorji, Mohamed; Reza Ahmed khaniha and Mojtaba Moazzen (2016): polycyclic aromatic hydrocarbons in Iranian Kebabs. Food Control Journal 60: 57-63.

Hazra, B.; Sarkar, R.; Biswas, S. and Mandal, N. (2010): Comparative study of the antioxidant and re-active oxygen species scavenging properties in the extracts of the fruits of Terminaliachebula, Terminaliabelerica and Emblica of cinalis. BMC Complement. Altern. Med. 10 (1), 20.

Kazerouni, N.; Sinha, R.; Hsu, C.H.; Greenberg, A. and Rothmann, N. (2001): Analysis of 200 food items for benzo (a) pyrene and estimation of its intake in an epidemiologic study. Food and Chemical Toxicology, 39, 423-436.

Laing, D.G. and Jink, A. (1996): Flavour perception mechanisms. Trends Food Sci., Tech: 27(7).

Nisbet, I.C.T. and LaGoy, P.K. (1992): Toxic equivalency factor (TEFS) for polycyclic aromatic hydrocarbons (PAHs). Regulatory Toxicology and Pharmacology, 16, 290-300.

Nursten, H. (2005): The Maillard reaction, chemistry, biochemistry and implications (pp. 151-152). The University of Reading, UK: The Royal Society of Chemistry.

Orecchio, S. and Papuzza, V. (2009): Levels, fingerprint and daily intake of polycyclic aromatichydrocarbons (PAHs) in bread baked using wood as fuel. J. Hazard. Mater. 164 (2), 876-883

Mishref, M. (2014): Assessment of some polycyclic aromatic hydrocarbon in prefabricated meat for consumption and its relevance to food safety. PHD Thesis Zagazig University.

Moret, S. and Conte, L.S. (2000): Polycyclic aromatic hydrocarbon in edible fats and oils: occurrence and analytical methods Journal of chromatography A, 882: 245-253.

Phillips, D.H. (1999): Polycyclic aromatic hydrocarbons in the diet. Mutation Research/Genetic Toxicology and Environmental Mutagenesis, 443(1), 139-147. 
Reinik, M.; Tamme, T.; Roasto, M.; Juhkam, K.; Tenno, T. and Kiis, A. (2007): Polycyclic aromatic hydrocarbons (PAHs) in meat products and estimated PAH intake by children and the general population in Estonia. Food Additives \& Contaminants Part A, 24, 429-43.

Sundararajan, N.; Sundararajan Nadife, M.; Basel, R. and Green, S. (1999): "Comparison of sensory properties of hamburgers cooked by conventional and carcinogen reducing safe grill” equipment. Meat Science, 51, 289-295.

Shon, M.Y.; Chois, S.D.; Kahng, G.G.; Nam, S.H. and Sung, N.J. (2004): Antimutagenic antioxidant and free radical scavenging activity of ethyl acetate from white, yellow and red onion. Food and Chemical Toxicology, 42, 659-666.

Simko, P. (2002): Determination of polycyclic aromatic hydrocarbons in smoked meat products and smoke flavouring food additives. Journal of chromatography B, 770 (1), 3-18

Terzi, G.; Celik, T. and Nisbet, C. (2008): Determination of benzo [a] pyrene in Turkish döner Kebab samples cooked with charcoal or gas fire.Irish Journal of Agricultural and Food Research, 47, 187-193.

U.S. Environmental Protection Agency (US EPA) (2002): Polycyclic organic matter. Washington, DC: Environmental Prptection Agency Avalible from: http// www. Epa. gov/ $\mathrm{ttn} / \mathrm{atw} / \mathrm{hlthe} /$ polycycl html.

Villwneuve, J.P.; Carvalho, F.P.; Fowler, S.W. and Cattini, C. (1999): Levels and trends of PCBS, chlorinated pesticides and petroleum hydrocarbons in mussels from the NW Mediterranean coast: Comparison of concentration in 1973/1974 and 1988/1989. The Science of the total Environment. 237238, 57-65.

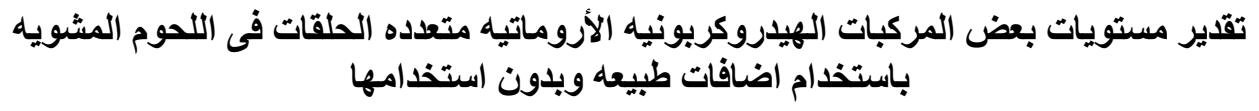

أروى حسن نصار ، صالح شفيق محد ، أسامسه عبل العظبم بيونس

E-mail: $\underline{\text { basma22toto@gmail.com Assiut University web-site: www.aun.edu.eg }}$

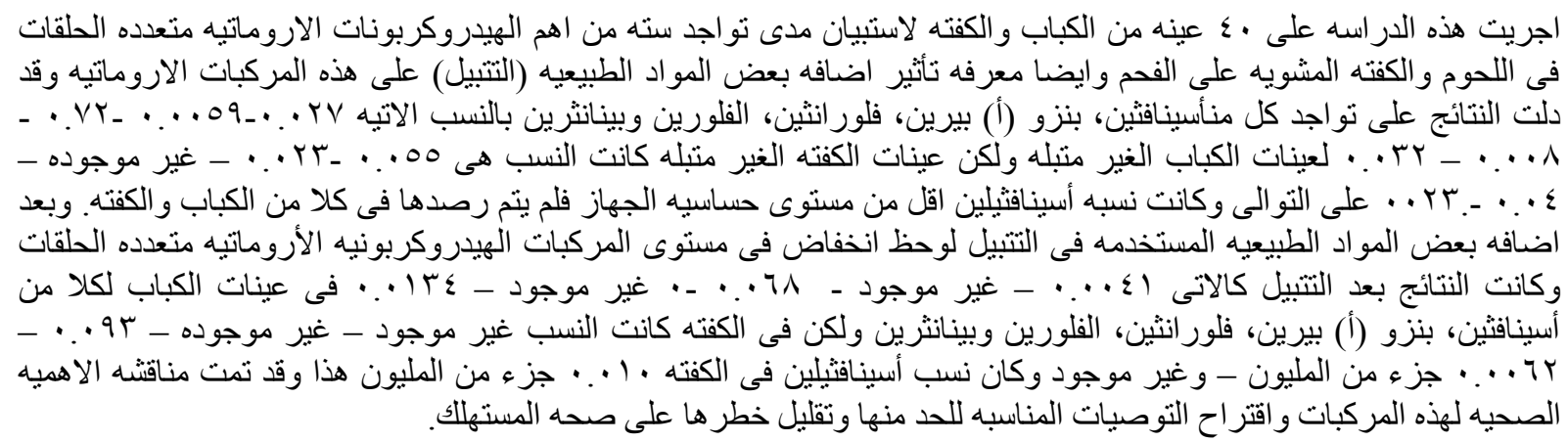

